\title{
An improved method to obtain antigen-excreting Toxocara canis larvae
}

\author{
Neuza Maria Alcântara-Neves ${ }^{\mathrm{a}, *}$, Alex Barbosa dos Santos ${ }^{\mathrm{a}}$, Lívia Ribeiro Mendonça ${ }^{\mathrm{a}}$, \\ Camila A.V. Figueiredo ${ }^{\mathrm{a}}$, Lain Pontes-de-Carvalho ${ }^{\mathrm{b}, \mathrm{c}}$ \\ a Instituto de Ciências da Saúde, Universidade Federal da Bahia, Avenida Reitor Miguel Calmon, Sem No, Canela, 41110-100 Salvador, Bahia, Brazil \\ ${ }^{\mathrm{b}}$ Centro de Pesquisa Gonçalo Moniz - CPqGM, Fundação Oswaldo Cruz - Fiocruz, Rua Waldemar Falcão, 121, Candeal - 40296-710- Salvador, Bahia, Brazil

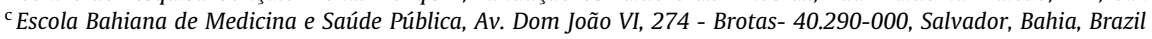

\section{A R T I C L E I N F O}

\section{Article history:}

Received 13 December 2007

Received in revised form 28 February 2008

Accepted 13 March 2008

Available online 23 March 2008

Index Descriptors and Abbreviations:

ESLA, excretory-secretory larval antigens

ELISA, enzyme-linked immunosorbent assay

Toxocara canis

Larva purification

Excretory-secretory larval antigen, ESLA

\begin{abstract}
A B S T R A C T
Toxocara canis is a dog helminth which causes visceral larva migrans (VLM) when infecting humans as a larva. The infection is demonstrated by detecting IgG antibodies against excretory-secretory larval antigens (ESLA) in serum by ELISA. The production of ESLA involves the collection of adult worms from dog puppy stools, the separation of eggs from dissected uteri, and the in vitro growing of egg-derived larvae, following the time-consuming and laborious protocol described by De Savigny [De Savigny, D.H., 1975. In vitro maintenance of $T$. canis larvae and a simple method for the production of Toxocara ES antigen for the uses in serodiagnostic tests for visceral larva migrans. Journal of Parasitology 61, 781-782]. In this work, an improved protocol for obtaining $T$. canis larvae is described. The modifications proposed improved the efficiency of the original De Savigny method in three ways: (i) increasing the parasite yield up to five fold, (ii) improving the larval purity, and (iii) markedly reducing the execution time of the protocol.
\end{abstract}

(c) 2008 Elsevier Inc. All rights reserved.

\section{Introduction}

Visceral and ocular larva migrans are prolonged infectious diseases caused by the migration of helminth larvae in internal organs and eyes of parathenic hosts, leading to high eosinophil production (Despommier, 2003). The disease was first described by Wilder (1950) and Beaver and collaborators (1952), after examining several children with eosinophilia and chronic illness, reported that Toxocara canis and Toxocara cati were the agents of a disease that they called visceral larvae migrans (VLM). VLM may occur systemically, associated with fever and hepatosplenomegaly, with asthma-like (Kuziemski et al., 1999) and neurological syndromes (Magnaval et al.,1997). The clinical manifestations of VLM are often non-specific, resulting in substantial underdiagnosis (Mirdha and Khokar, 2002). Sero-epidemiological surveys suggest that Toxocara infection may occur frequently, in most cases asymptomatically (Kayes, 1997). T. canis infection occurs worldwide and its prevalence is higher in developing countries and in low-income populations than in developed countries and high-income populations (Despommier, 2003). Since the larvae inhabit the internal organs, where they are not easily detected, the diagnosis of the disease and infection is serological. The most used method is an indirect ELISA, which detects antibodies against excretory-secretory larval antigens (ESLA). ESLA are obtained from in vitro cultures, as de-

\footnotetext{
* Corresponding author. Fax: +55 7132458917.

E-mail address: neuza@ufba.br (N.M. Alcântara-Neves).
}

scribed by De Savigny (1975). Pre-absorption of serum samples with Ascaris sp. somatic antigen confers high specificity to the assay (De Savigny and Tizard, 1975; De Savigny et al., 1979). In addition to crude ESLA, other antigen preparations have been used in the ELISA, such as purified ESLA molecules (Iddawella et al., 2007) and recombinant antigen (Hiroshi et al., 2000; Coelho et al., 2003). This latter, despite having improved the ELISA specificity (Hiroshi et al., 2000), is not extensively used. In addition to its use in serodiagnosis, ESLA is also used in in vitro and in vivo studies on the immunomodulatory effects of $T$. canis products (Spinoza et al., 2002). However, obtaining ESLA, as described by De Savigny (1975), is time-consuming and laborious. Our work describes modifications of this method which significantly improved, quantitatively and qualitatively, the obtaining of $T$. canis larvae.

\section{Materials and methods}

Pregnant worms were obtained by treatment of puppies with piperazine salts (LAFERE, São Paulo, SP, Brazil) at a dose of $0.3 \mathrm{~g} /$ $\mathrm{kg}$ body weight. The female worms were washed thoroughly and their uteri were dissected. The anterior non-bifurcated small portion of the uterus, where the proportion of embryonated eggs is higher than in the remainder of the uterus, was separated from the bifurcated portion, where the eggs, although less frequently embryonated, are present in higher numbers. The eggs, obtained from dissection of both portions, were incubated in $4 \%$ formalin (VETEC, São Paulo, Brazil) for 35 days, until embryonation. To dis- 
solve the mamilonated membrane, the eggs were incubated in a $5 \%$ sodium hypochlorite (REATEC, São Paulo, SP, Brazil) water solution, for $5 \mathrm{~min}$ at room temperature. The eggs hatching was accomplished by incubating them in a bottle containing RPMI (Sigma Chemical Co., St. Louis, CA, USA) and sterile glass beads, and gently shaking by hand for 3-5 min. To change the solutions in which the eggs were suspended (from the formalin to the sodium hypochlorite solution, and from this latter solution to RPMI), two different procedures were used: (i) the one recommended by De Savigny (1975), i.e., three washings by centrifugation in sterile water, for each solution and (ii) filtration through a $4 \mathrm{~cm}$-diameter PVC filter, containing a stainless-steel sieve (TELAS TOKYO, São Paulo, Brazil) with $20-\mu \mathrm{m}$ pores. In this case, the incubation of the eggs with sodium hypochlorite was done by placing the filter with the eggs inside a Petri dish containing the salt solution (Fig. 1A). After larval hatching, the suspension containing non-embryonated eggs, egg shells and larvae was either, in the case of the material washed by centrifugation (De Savigny, 1975), applied to a Baermann's apparatus (Fig. 1B), or the larvae were separated from the eggs by filtration on the stainless-steel sieve mentioned above, by placing the filter onto a $250 \mathrm{~mL}$ conical glass cup which, in its turn, was dipped into a beaker containing warm water (Fig. 1C). A warmed solution of $0.15 \mathrm{M}$ phosphate-buffered saline, $\mathrm{pH} 7.4$, containing $1 \%$ glucose (PBS-G), was poured onto the funnel of the Baermann's apparatus or on the cup of the modified Savigny's method, until its surface touched the larvae. This procedure allows the larvae to migrate into the PBS-G, based on their thermo- and hydrotropism. In the modified method the temperature was maintained by replacing the warm water in the beaker. The comparison between the two protocols was done by counting the larvae and eggs in $25 \mu \mathrm{L}$ volumes of the larval suspensions, placed in triplicate, in glass
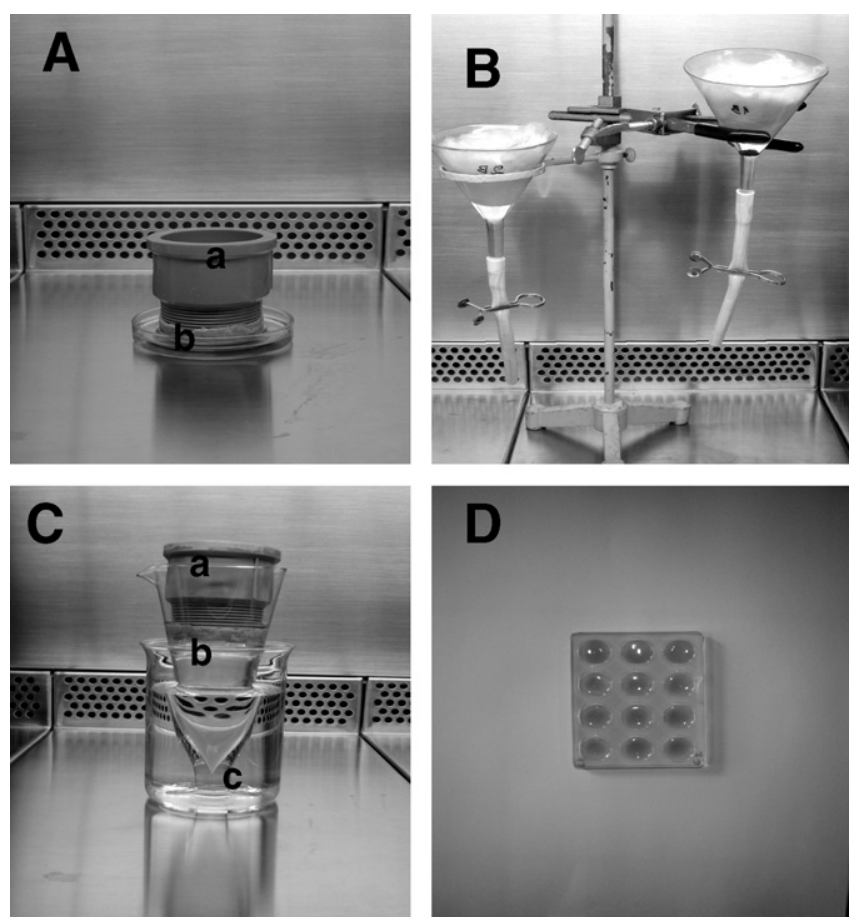

Fig. 1. (A) Device for egg incubation and filtration in the modified De Savigny's method. Note a filter holder (a) dipped into a Petri dish (b) containing sodium hypochlorite. (B) Baermann's apparatus. (C) Device for purification of larvae in the modified De Savigny's method. Note the filter holder (a) dipped in a conical glass cup (b) containing a sterile solution of $1 \%$ glucose in $0.15 \mathrm{M}$ phosphate-buffered saline, which, in its turn, is dipped into a beaker (c) containing warm distilled water. (D) Glass slide for counting eggs and larvae in an inverted microscope. chambers (Fig. 1D), using an inverted microscope. The duration of each protocol was measured and was repeated three times.

\section{Statistical analysis}

Differences in egg and larval yields were analyzed by the Wilcoxon's signed rank test. $P$ values less than 0.05 were considered statistically significant.

\section{Results and discussion}

To carry out studies aimed at improving the diagnosis of VLM, an important first step is to obtain sufficient quantities of ESLA. We modified several steps in the standard protocol for obtaining ESLA-producing $T$. canis larvae to improve larval yield and purity and shorten the duration of the procedures. The type of washing procedure (centrifugation or sieving) did not affect egg yields $(P>0.05$, Wilcoxon's signed rank sum test, data not shown) but the modification made the washings easier and faster. The De Savigny's method recommends using only the anterior portion of the uterus, probably due to the high egg contamination of the larval preparation when the posterior portion was used. In the modified method, the posterior segment of uterus yielded the same number of larvae as the anterior segment, without egg contamination (Table 1). This was attributed to the use of the stainless sieve in the modified method, without the thick layers of gauze and cotton

Table 1

Comparison between methods of $T$. canis larvae purification

\begin{tabular}{|c|c|c|c|c|c|c|c|c|}
\hline \multirow{2}{*}{$\begin{array}{l}\text { Uterus } \\
\text { portion }\end{array}$} & \multicolumn{2}{|c|}{ No. of larvae ${ }^{a}$} & \multirow[t]{2}{*}{$\%^{\mathrm{b}}$} & \multirow{2}{*}{$\begin{array}{l}\text { No. of } \\
\text { eggs }^{c}\end{array}$} & \multicolumn{2}{|c|}{ No. of larvae ${ }^{a}$} & \multirow[t]{2}{*}{$\%^{\mathrm{b}}$} & \multirow{2}{*}{$\begin{array}{l}\text { No. of } \\
\text { eggs }^{c}\end{array}$} \\
\hline & $\begin{array}{l}\text { Before } \\
\text { Baermann }\end{array}$ & $\begin{array}{l}\text { After } \\
\text { Baermann }\end{array}$ & & & $\begin{array}{l}\text { Before } \\
\text { filtration }\end{array}$ & $\begin{array}{l}\text { Post } \\
\text { filtration }\end{array}$ & & \\
\hline Posterior & 32 & 12 & 37.5 & 16.1 & 26 & 20 & 78.1 & 0.0 \\
\hline Anterior & 38 & 15 & 39.5 & 0.5 & 39 & 31 & 79.6 & 0.0 \\
\hline Anterior & 35 & 14 & 41.0 & 10 & 35 & 35 & 100 & 0.0 \\
\hline Anterior & 51 & 15 & 29.0 & ND & 59 & 44 & 76.0 & ND \\
\hline Posterior & 36 & 09 & 25.0 & 60 & 34 & 32 & 95.2 & 0.0 \\
\hline
\end{tabular}

${ }^{a} P=0.043$; Wilcoxon's signed ranks test for the observed differences between the procedures.

b Percentage of larval numbers are means of triplicate counts $\times 10^{3}$.

c Number of non-embryonated eggs contaminating the larval preparations are means of triplicate counts.
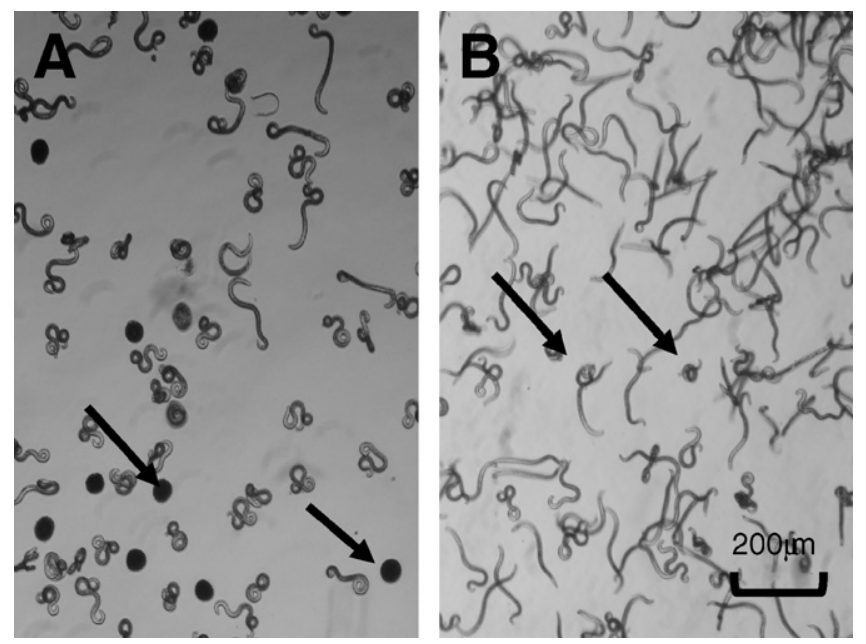

Fig. 2. Toxocara canis larvae purified by De Savigny's (A) and modified De Savigny's (B) methods. The arrows in (A) point to one egg and in (B), point to a curled larvae. Magnification $100 \times$. 
Table 2

Larva yields in De Savigny's and modified De Savigny's methods

\begin{tabular}{|c|c|c|c|c|c|}
\hline \multirow[t]{2}{*}{ Experiment } & \multicolumn{2}{|c|}{ No. of purified larvae in } & \multicolumn{2}{|c|}{ No. of contaminating eggs in } & \multirow{2}{*}{$\begin{array}{l}\text { No. of larvae in modified method/no. of larvae in } \\
\text { De Savigny's method }\end{array}$} \\
\hline & De Savigny's method & Modified method & De Savigny's method & Modified method & \\
\hline 1 & $15^{\mathrm{a}}$ & 76 & $0.5^{\mathrm{b}}$ & 0.0 & 5.1 \\
\hline 2 & 14 & 67 & 10.0 & 0.0 & 4.8 \\
\hline
\end{tabular}

a Number of larvae $\times 10^{3}$.

b Number of contaminating eggs in the larva preparations $\times 10^{3}$.

Table 3

Time for performing different procedures in the De Savigny's and the modified De Savigny's methods for T. canis larva purification

\begin{tabular}{lll}
\hline Procedure & Time spent in \\
\cline { 2 - 3 } & $\begin{array}{l}\text { De Savigny's } \\
\text { method }\end{array}$ & $\begin{array}{l}\text { Modified } \\
\text { method }\end{array}$ \\
\hline Formalin and sodium hypochlorite washings & $\begin{array}{l}60 \mathrm{~min} \\
12.0 \mathrm{~h}\end{array}$ & $\begin{array}{l}6 \mathrm{~min} \\
\text { Larva purification and collection }\end{array}$ \\
Total time of method & $13.0 \mathrm{~h}$ & $4.1 \mathrm{~h}$ \\
\hline
\end{tabular}

of the Baermann's apparatus used in the De Savigny's method, which pack the eggs and allow the transport of part of them together with the larvae. The larval yields were 1.7-3.8 times higher when purified by filtration than on the Baermann's apparatus $(P<0.05$, Wilcoxon's signed ranks test; Table 1$)$. Eggs contaminated the larva preparations obtained with the use of the Baermann's apparatus, but not those obtained using the metal-mesh sieve (Table 1 and Fig. 2). The overall larval yield was about 5.0 times higher (Table 2) and the time spent in performing the modified method was substantially shorter (4.1 and $13 \mathrm{~h}$; Table 3 ) in the modified method compared to the De Savigny's method. The sieve allows the larvae to migrate more actively through the pores, leaving eggs and egg shells behind. Obtaining large amounts of $T$. canis ESLA is a difficult task. This stems both from the scarcity, mainly in developed countries, of T. canis-infected puppies, and from the relatively low larva numbers by the De Savigny's protocol. The modified protocol requires only one infected puppy to produce the amount of larvae previously obtained from five infected puppies, in a fraction of the time, and may be of value to investigators working on VLM epidemiology, the development of VLM serodiagnostic assays, the biological effect of ESLA components on individuals with VLM, or the biology of the T. canis larvae themselves.

\section{Acknowledgments}

The study was conducted through the SCAALA (Social Change, Asthma and Allergy in Latin America) initiative, funded by the Wellcome Trust Grant No. 072405/Z/03/Z and also by Fundação de Amparo a Pesquisa do Estado da Bahia (FAPESB), which supplied fellowships for C.A.V. Figueiredo and L.R. Mendonça. A.B. Santos had a Conselho Nacional de Desenvolvimento Científico e Tecnológico (PIBIC-CNPq) scholarship. We are thankful to Dr. Pedro Chieffi for information on the purification of $T$. canis larvae by the De Savigny's method.

\section{References}

Beaver, P.C., Snyde, C.H., Carrera, G.M., 1962. Chronic eosinophilia due to visceral larva migrans. Pediatrics 9:7-19. Toxocarosis (visceral larva migrans) in relation to tropical eosinophilia. Bulletin of the Exotic Pathology Society 55, 555-576.

Coelho, R.A., Yamasaki, H., Perez, E., de Carvalho Jr., L.B., 2003. The use of polysiloxane/polyvinyl alcohol beads as solid phase in IgG anti-Toxocara canis detection using a recombinant antigen. Memórias do Instituto Oswaldo Cruz 98 (3), 391-393.

De Savigny, D.H., 1975. In vitro maintenance of Toxocara canis larvae and a simple method for the production of Toxocara ES antigen for the uses in serodiagnostic tests for visceral larva migrans. Journal of Parasitology 61, 781-782.

De Savigny, D.H., Tizard, I.R., 1975. Serodiagnosis of Toxocara larva migrans visceral. Canadian Journal of Public Health 66, 52-56.

De Savigny, D.H., Voller, A., Woodruff, A.W., 1979. Toxocariasis: serological diagnosis by enzyme immunoassay. Journal of Clinical Pathology 32, 284-288.

Despommier, D., 2003. Toxocariasis: clinical aspects, epidemiological, medical ecology and molecular aspects. Clinical Microbiological Reviews 16 (2), 265272.

Hiroshi, Y., Araki, K., Lim, P.K.C., Zasm, Y.N., Mak, J.W., Taib, R., Aoki, T., 2000. Development of a highly specific recombinant Toxocara canis second stage larva excretory-secretory antigen for immunodiagnosis of human toxocariasis. Journal of Clinical Microbiology 38 (4), 1409-1415.

Iddawella, R.D., Rajapakse, R.P.V.J., Pereira, N.A.N.D., Agatsuma, T., 2007. Characterization of a Toxocara canis species-specific excretory-secretory antigen (TcES-57) and development of a double sandwich ELISA for diagnosis of visceral larva migrans. Korean Journal of Parasitology 45 (1), 19-26.

Kayes, S.G., 1997. Human toxocariasis and the visceral larva migrans syndrome: correlative immunopathology. Chemical Immunology 66, 99-124.

Kuziemski, K., Jassem, E., Mierzewska, E., 1999. Lung manifestation of visceral larva migration syndrome due to Toxocara canis. Pneumologia i Alergologia Polska 67, 554-557.

Magnaval, J.F., Galindo, V., Glickman, L.T., Clanet, M., 1997. Human Toxocara infection of the central nervous system and neurological disorders: a case control study. Parasitology 115, 537-543.

Mirdha, B.J., Khokar, S.K., 2002. Ocular toxocariasis in a North Indian population. Journal of Tropical Pediatrics 48, 328-330.

Spinoza, E., Muro, A., Martins, M.M.S., Casanueva, P., Pérez-Arellano, J.S., 2002. Toxocara stimulates the production of nitric oxide and prostaglandin E2 by rat alveolar macrophages. Parasite immunology 24, 311-319.

Wilder, H.C., 1950. Nematode endophthalmitis. Transaction of the American Academy of Opthalmology 55, 99-100. 